\title{
GENERAL PRACTICE : THE CORNERSTONE OF HEALTH CARE IN THE THIRD MILLENIUM
}

Strasser $\mathbf{R}^{1}$

\section{ABSTRACT}

As we move into the third millennium, it is clear that the World Health Organisation (WHO) goal of "Health for All" is yet to be achieved. Nowhere is this more evident than in developing countries like Nepal where the majority of people live in rural areas, many of them caught in the poverty-ill health-low productivity downward spiral. In recent decades, most programs aimed at improving population health outcomes have been designed and delivered with little or no involvement of medical practitioners other than specialists in specific diseases or population/public health.

General practice is the medical discipline which involves the provision of continuing, comprehensive, community-based patient-centred prevention-oriented primary care. General practitioners are at the interface between: low technology/low cost and high technology/high cost care; medical and non-medical health and welfare services; and individual care for illness, injury or disability and community/population health approaches to improving health status. This places general practice and general practitioners in a pivotal position to provide individuals and families with timely costeffective care, and to provide leadership in the development and implementation of health care systems which are responsive to community and societal needs.

Since 1994, the WHO and WONCA, the World Organisation of Family Doctors, have been working together first through a landmark Invitational Conference and Report on "Making Medical Practice and Education More Relevant to People's Needs: The Contribution of the Family Doctor", and more recently through a Memorandum of Agreement and the Towards Unity for Health (TUFH) Project. TUFH promotes efforts worldwide to create unity in health service organisations particularly through sustainable integration of medicine and public health, individual health and community health related activities. Achievement of "Health for All" will require development of balanced, affordable and sustainable health care systems which build on the broad expertise of general practitioners and general practice.

1. Head, Monash University School of Rural Health, Australia

Address for correspondence : $\quad$ Prof. Roger Strasser, Head, Monash University School of Rural Health Post Office Box: 424, Traralgon, Victoria 3844, Australia

Telephone No.: +61 35173 8181, Fax: +61 351738182

Email: roger.strasser@med.monash.edu.au 


\section{HEALTH FOR ALL}

The year 2000 has passed and clearly we have not attained Health for All. The Health for All program was enunciated through the Declaration of Alma Ata in 1978. That Declaration said, in part, "that health is a state of complete physical, mental and social well-being and not merely the absence of disease or infirmity. That health is a fundamental human right and that the attainment of the highest possible level of health is a most important world wide social goal." ${ }^{2}$ It went on to say:

"Governments have a responsibility for the health of their people which can be fulfilled only by the provision of adequate health and social measures. A main social target of governments, international organisations and the whole world community in the coming decades should be the attainment by all peoples of the world by the year 2000 of a level of health that will permit them to lead a socially and economically productive life. Primary Health Care is the key to attaining this target as part of development in the spirit of social justice. Primary Health Care is the first level of contact of individuals, the family and community with the national health system bringing health care as close as possible to where people live and work and constitutes the first element of a continuing health care process. Primary Health Care addresses the main health problems in the community providing promotive, preventive, curative and rehabilitative services accordingly. "

\section{THE PROBLEMS WITH PRIMARY HEALTH CARE}

The Declaration of Alma Ata outlined a grand vision of Primary Health Care which has not yet been achieved. In retrospect there have been a series of problems with the interpretation and implementation of Primary Health Care.

\section{Table 1: The Problems with Health Care}

1. Bureaucratic Interpretation

2. Selective Vertical Programs

3. Dismissal of Curative Interventions

4. Clinicians Excluded

The first problem relates to the bureaucratic context. This was well outlined by Judith Justice, "The Bureaucratic Context of International Health: A Social Scientist's View". 3 In part she says "many Primary Health Care programs were ineffective, as research undertaken in Nepal has shown, because they reflect the perspective and needs of the health bureaucracies involved rather than those of the local villages receiving services. Work in other south and south-east Asian countries reveals that Primary Health Care was interpreted differently in different bureaucratic settings and adapted to bureaucratic needs but not necessarily adapted to the village cultures and conditions."

Another issue was outlined in a paper in The Lancet by McFarlane et al, ${ }^{4}$ which says in part: "the Declaration of Alma Ata in 1978 the ideal of which was that health was attainable for and by the people in a comprehensive fashion, yet the Alma Ata was immediately followed by a series of northerndesigned selective initiatives which are still be generated today. Selective vertical programs enabled the International Aid Agencies to measure results and protect their investments from complicated long-term multi-sectoral and interdepartmental implementation. Non government organisations and religious groups have found that holistic community-based health programs are generally undermined by narrowly selective interventions and that the sustainability of peopleowned initiatives can be put in jeopardy."

A third problem is the tendency of Primary Health Care Programs to dismiss curative interventions and ignore the desire people have for some help 
with their immediate health problems. There was a program in Nepal, the Nutrition Education Intervention Program ${ }^{5}$ which was evaluated some years ago and that did involve some curative intervention. The evaluators found that the inclusion of curative activities in the program seemed to be a key factor in increasing the motivation of participants and acceptance by the community so contributing to the success of the program.

A fourth problem is the tendency to exclude practising clinicians. As the notions of Primary Health Care were developed, the strong emphasis was on disease prevention and health promotion. Consequently, the development over the years of the community health cum public health cum population health approach focused on healthy lifestyle and "wellness" in the extreme, to the point of excluding the practitioners, the cliniciansdoctors, nurses and others who are perceived to be dealing with ill health. That dichotomy created tension which has created difficulties. In most of the World Health Organisation and the other Primary Health Care programs around the world, there has been little medical involvement, other than by specialists in public health or in specific diseases in program planning. Implementation in the field has tended not to involve clinicians, and particularly not to involve doctors.

The reality is that 1.3 billion people, nearly a quarter of the world's population, are poor. In terms of health indicators, 766 million people in developing countries lack access to health services. In Asia $60 \%$ of the poor live on marginal lands of low productivity and high susceptibility to degradation. ${ }^{6}$ Clearly they are caught in the poverty - ill health - low productivity downward spiral.

The focus on poverty and social and economic difficulties has led to a tendency to address those issues and not directly to address health issues. In fact, there is view that this is not the way to go. The 10/90 Report on Health Research 1999 notes: "The global community should recognise that good health is a way out of poverty. It results in a greater sense of wellbeing and contributes to increased social and economic productivity. The impact of ill health on productivity affects not only the poor but societies and economies as well." So clearly it is important to focus on improving health, as part of improving economic and social wellbeing.

\section{GENERAL PRACTICE}

General practice is the provision of primary continuing comprehensive community-oriented patient-centred preventive care. ${ }^{7}$ In a real sense general practice requires the doctor to be the first contact accepting all patients irrespective of age, sex or the nature of their problem. Implicit in this concept of general practice is the perspective that illness and suffering are related as much to the context of the person's life experience and life circumstances as to the particular disease caused by a specific agent.

As a generalist, the general practitioner is not tied to a specific group of diseases or type of patient or set of technical skills, but rather is committed to the person who is the patient. This may include involving other doctors including specialists or other health professionals and agencies in the community. In this sense the general practitioner is a key person in the network of community health services linking the patient to available community support and resources.

A general practitioner is a doctor who accepts all kinds of people with all kinds of problems. They may be presenting very early in the natural history of their problem or very late, and the general practitioner has to deal with that level of 
uncertainty. There is clearly an emphasis on personal care. In developing countries, it is very common, particularly in rural areas, for the general practitioner to be hospital-based.

It is important to recognise that a general practitioner is not a "jack of all trades and a master of none". Rather, a general practitioner is a highly trained "specialist generalist" who is skilled at dealing with the full range of common health problems, acute and chronic as they present. In fact in Nepal, the MDGP Program has the objective to prepare doctors to be district health officers in the rural hospitals. They are expected to be able to deal with all common problems and also to be able to respond to life-threatening situations as well.

Martha Carlough from the United States of America spent quite a number of years in Nepal under the Interserve USA Program. She wrote a paper describing how she sees the commonality in family practice or general practice in her experience in Nepal with the United States. In part, she says:

"As a physician working in Nepal, my practice of family and community medicine may seem quite different from that of most of my colleagues in the United States. The practice setting is a small general hospital that is a three-day walk from the nearest road, an average of 200 patients per day are cared for by three doctors with Nepalese support staff. We are also involved in supporting community health and development in surrounding villages and teaching midwives and other village level health workers. It is a simple way to practice medicine yet full of difficulties, pain and loss. Daily we are faced with issues of abject poverty, illiteracy, gender inequity and a lack of resources. Patients arriving at our door have often spent most of their money to pay for porters to carry them to the hospital. Most have consulted a traditional healer before they reach us. Many have illnesses complicated by lives of too much work and too little nutritious food and clean water."

She then goes on in this paper to talk about the United States context of family practice and she links together what she sees as the common themes. They are "our patients are not only those who come to see us". "Every encounter is influenced by family relationships, cultural tradition and socio-economic status." So a key theme of general practice or family practice or family medicine is the focus on caring for and understanding a persons situation in the context of their home, family and community.

The general practitioner also has a role as a gatekeeper. The main literature on this comes from the USA and is very much focused on cost control. $^{9,10}$ This is actually quite a distortion of the importance of the role of the general practitioner as the first contact doctor. Gatekeeping is much more about clinical decision making. ${ }^{11}$ A trained general practitioner is able to deal with $80-90 \%$ of the clinical problems that present and is well able to select which patients need the specific high technology specialist care. The general practitioner is at the interface between low cost/low technology medicine and high cost/high technology medicine and specialist care. Also the general practitioner is well placed to determine which patients in fact would benefit from non medical health services. Coming back to the issues of public health/ community health/population health, the general practitioner is well placed to provide that link between individual and family health care and community and population health.

Another important role of the general practitioner is that of patient advocate. ${ }^{6}$ The general practitioner represents the interests of the patient and community to health authorities and, at times, acts as "translator" helping patients to understand the system. 


\section{THE HEALTH CARE SYSTEM}

In 1998, the World Health Assembly could see 2000 coming and made new commitments to Health for All policy for the $21^{\text {st }}$ Century. ${ }^{12}$ The commitment included in part: "we commit ourselves to strengthening, adapting and reforming as appropriate our health systems including essential public health functions and services in order to ensure universal access to health services that are based on scientific evidence of good quality and within affordable limits and that are sustainable for the future. We will continue to develop health systems to respond to the current and anticipated health conditions, socio-economic circumstances and the needs of people, communities, and countries concerned to appropriately manage public and private actions and investments in health."

General practice is pivotal to the development of health systems as outlined by the World Health Assembly. It is also important to have a full health team. This involves not only doctors, but also nurses and other health professionals including medical assistants. ${ }^{13}$ The Health Care Team should not only respond to immediate health care needs with a focus on treatment, cure, and care, but also on health education and health promotion. This contributes to a balanced health care system. Another important factor is strong and active community involvement. This helps to overcome difficulties identified with previous Primary Health Care Programs. Health systems work best when there is active community participation. ${ }^{14}$

\section{INTERNATIONAL DEVELOPMENTS}

There are some important developments over the last ten years with the World Health Organisation and WONCA, the World Organisation of Family Doctors. The WHO seems to have recognised the need for doctors in the field as part of the Primary Health Care team. WHO formed a collaboration with WONCA first in 1994 with an Invitational Conference on Making Medical Education Better Suited to People's Needs ${ }^{15}$ which led to major changes in medical education around the world. To some extent, the report of that Conference provided a framework for development of the curricula of the new Medical Colleges in Nepal.

More recently WHO and WONCA has initiated the Towards Unity for Health Program ${ }^{16}$ which has the specific aim of integrating the individual health and the population health perspectives towards achieving a more effective and efficient health system. In 1998 the WHO and WONCA signed a Memorandum of Agreement ${ }^{17}$ to work together which includes a Rural Health Initiative. WHO and WONCA are planning an Invitational Conference on Rural Health to be held at the Monash School of Rural Health, Traralgon, Australia in April which will bring together the people from governments, from medical colleges and health education institutions, practitioners from the field and health service planners to put together a global plan for improving the health of all rural people around the world.

\section{CONCLUSION}

Recognising the shortcomings of the previous Health for All and Primary Health Care programs and the nature of general practice, it is clear that general practice has much to contribute to a balanced and effective health care system. A strong and effective general practice is essential to a successful health care system. 


\section{REFERENCES}

1. Bergstrom S, Mocumbi P. Health for all by the year 2000? BMJ 1996; 10: 313:316.

2. World Health Organisation. The Declaration of Alma-Ata. The International Conference on Primary Health Care, 1978.

3. Justice J. The Bureaucratic Context of Intemational Health: A.Social Scientist's View. Soc. Sci. Med. 1987; 25: 11301-1306.

4. McFarlane S; Racelis M, Muli-Musiime F. Public Health in Developing Countries. The Lancet. 2000; 356: 841-846.

5. Curtale F, et al. Improving Skills and Utilization of Community Health Volunteers in Nepal. Soc. Sci. Med 1995; 40: 1117-1125.

6. Global Forum for Health Research. 10/90 Report, Switzerland 1999

7. Strasser R. General Practice - What is it? Medical Journal of Australia, 1991; 155, 533534.

8. Carlough M C. Family Practice in Nepal: An International Perspective. Family Medicine, 30, No 8, 599-600.

9. Reagan MD. Physicians as gatekeepers - a complex challenge. New England Journal of Medicine, 1987; 317: 1731-1733.

10. Hurley RE, Freund DA and Gage BJ. Gatekeeper effects on patterns of physician use. Journal of Family Practice, 1991; 32: 167-173.
11. Strasser R. The gatekeeper role of general practice. The Medical Journal of Australia. 1992; 156.

12. World Health Organisation. The World Health Report: Life in the $21^{\text {st }}$ Century: A Vision for All. Geneva 1998

13. Strasser R. Teams in rural health. Rural health in New Zealand and Australia - part 2. Healthcare Review - Online ${ }^{\mathrm{TM}} 4$ (1); December 1999/ January 2000. http://www.enigma.co.nz/ hcro_articles/0001/vol4no1_001.htm

14. Strasser R, Worley P, Hays R \& Togno J. Developing social capital: Commity participation in rural health services. In H Pampling and G Gregory (Eds), Canberra: National Rural Health Alliance. 1999; 406-412.

15. Geneva World Health Organisation. Making medical practice and education more relevant to people's needs: the contribution of the family doctor. WHO/WONCA 1994 Conference: The contribution of the family doctor, 68 November 1994, London, Ontario, Canada. Available on request from Department of Organisation of Health Services Delivery, World Health Organisation, 1211 Geneva 27 Switzerland. 1995.

16. World Health Organisation. Towards Unity for Health: Challenges and Opportunities for Partnership in health Development. A Working Paper. Geneva 2000

17. The WHO-WONCA joint publication on making medical practice and education more relevant. 1995 www.wonca.org.publications/WONCAWHO/original/1995Report.htm

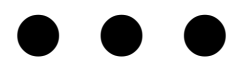

Note:- This review article is based on the keynote address by Prof. Roger Strasser in the Twentith All Nepal Medical Conference (ANEMECON-20) held in March 2001 with the theme "Doctors for Community in the Third Millennium". 